\title{
First report of Stemphylium solani causing leaf spot of Kalanchoe blossfeldiana in Taiwan
}

\author{
Y.M. Shen ${ }^{1}$, Y.C. Yang ${ }^{2}$, Y.J. Fu ${ }^{2}$ and T.H. Hung ${ }^{3 *}$ \\ ${ }^{1}$ Plant Protection Laboratory, Taichung District Agricultural Research and Extension Station, Dacun, Changhua, Taiwan; ${ }^{2}$ \\ Taipei Branch, Taoyuan District Agricultural Research and Extension Station, New Taipei, Taiwan; ${ }^{3}$ Department of Plant \\ Pathology and Microbiology, National Taiwan University, Taipei, Taiwan
}

*E-mail: thhung@ntu.edu.tw

Received: 28 Jul 2011. Published: 01 Mar 2012. Keywords: Pleospora, Pleosporaceae, Crassulaceae

Kalanchoe blossfeldiana is an economically important potted flower in Taiwan. Necrotic spots affecting both leaves and stems of this plant were recently discovered in different cultivated areas in Taiwan including Nantou, Miaoli, Taoyuan and Yilan Counties. The incidence of the disease was usually more than $80 \%$ in some severely diseased areas. Infected leaves produced tan or brown spots surrounded by chlorotic haloes (1-3 $\mathrm{mm}$ in diameter). These became raised and scab-like with age (Fig. 1). To identify the disease causing agent, tissue cut from edges of lesions was surface sterilised in $0.6 \% \mathrm{NaOCl}$ and plated on potato dextrose agar (PDA). Colonies of a Stemphylium sp. were consistently obtained from diseased samples. Cultures were greyish green to light brown and produced a yellow pigment (gradually turning brown or red with age) (Fig. 2a). Muriform, brown, oblong conidia (25.5-53.0 x 15.5-31.5 $\mu \mathrm{m})$ mostly constricted at the middle septum (Fig. $2 \mathrm{~b}$ ) were produced when exposed to alternate light and dark cycles $(12 \mathrm{~h} / 12 \mathrm{~h})$. Optimum temperature for growth of the fungus was between $24-28^{\circ} \mathrm{C}$. Molecular analysis was also conducted to identify the species of Stemphylium responsible. Internal transcribed spacer (ITS) sequences of three selected representative Stemphylium isolates were determined and deposited in GenBank (Accession Nos. JF913266, JF913268, JF913269). Alignment results showed that the sequences were $100 \%$ identical to S. solani (São Paulo tomato isolate No.1) (AF203451) (Mehta et al., 2002). Based on morphological criteria (Mehta, 1998; Kim et al., 2004; Sobers \& Seymour 1963) and molecular categorisation (Mehta et al., 2002), the pathogen was considered to be Stemphylium solani. Three voucher isolates (BCRC34730, BCRC34828 and BCRC34829) were deposited in the Bioresource Collection and Research Center, Hsinchu, Taiwan.

To complete Koch's postulates, healthy plants of $K$. blossfeldiana cv. 'Calandiva Bassey' were selected. A total of 12 plants were sprayed with $120 \mathrm{ml}$ of $S$. solani conidial suspension (approximately $8 \times 10^{3}$ conidia/ml) in $0.05 \%$ Tween 20 . An additional 12 plants were sprayed with $0.05 \%$ Tween 20 solution only, serving as negative controls. Brown leaf spots could be observed on young leaves one week after inoculation (Fig. 3a) and all inoculated plants exhibited lesions on leaves and stems one month after inoculation at $22^{\circ} \mathrm{C}$ (Fig. 3b). Control plants remained healthy. The pathogen re-isolated from the inoculated tissues was morphologically identical to the original isolate, thus fulfilling Koch's postulates. Several studies have reported Stemphylium sp. infecting Kalanchoe sp., but their morphology, optimum growth temperature and molecular sequence information differ from this finding (Sobers \& Seymour 1963; Sobers, 1965). This is the first report of $S$. solani causing leaf spot of $K$. blossfeldiana.

\section{References}

Kim BS, Yu SH, Cho HJ, Hwang HS, 2004. Gray leaf spot in peppers caused by Stemphylium solani and S. lycopersici. The Plant Pathology Journal 20, 85-91.

Mehta YR, 1998. Severe outbreak of Stemphylium leaf blight, a new disease of cotton in Brazil. Plant Disease 82, 333-336.

[doi:10.1094/PDIS.1998.82.3.333]

Mehta YR, Mehta A, Rosato YB, 2002. ERIC and REP-PCR banding patterns and sequence analysis of the internal transcribed spacer of rDNA of Stemphylium solani isolates from cotton. Current Microbiology 44, 323-328. [doi:10.1007/s00284-001-0026-4]

Sobers EK, 1965. A form of Stemphylium floridanum pathogenic to species of Kalanchoe. Phytopathology 55, 1313-1316.

Sobers EK, Seymour CP, 1963. Stemphylium leafspot of Echeveria, Kalanchoe, and Sedum. Phytopathology 53, 1443-1446.
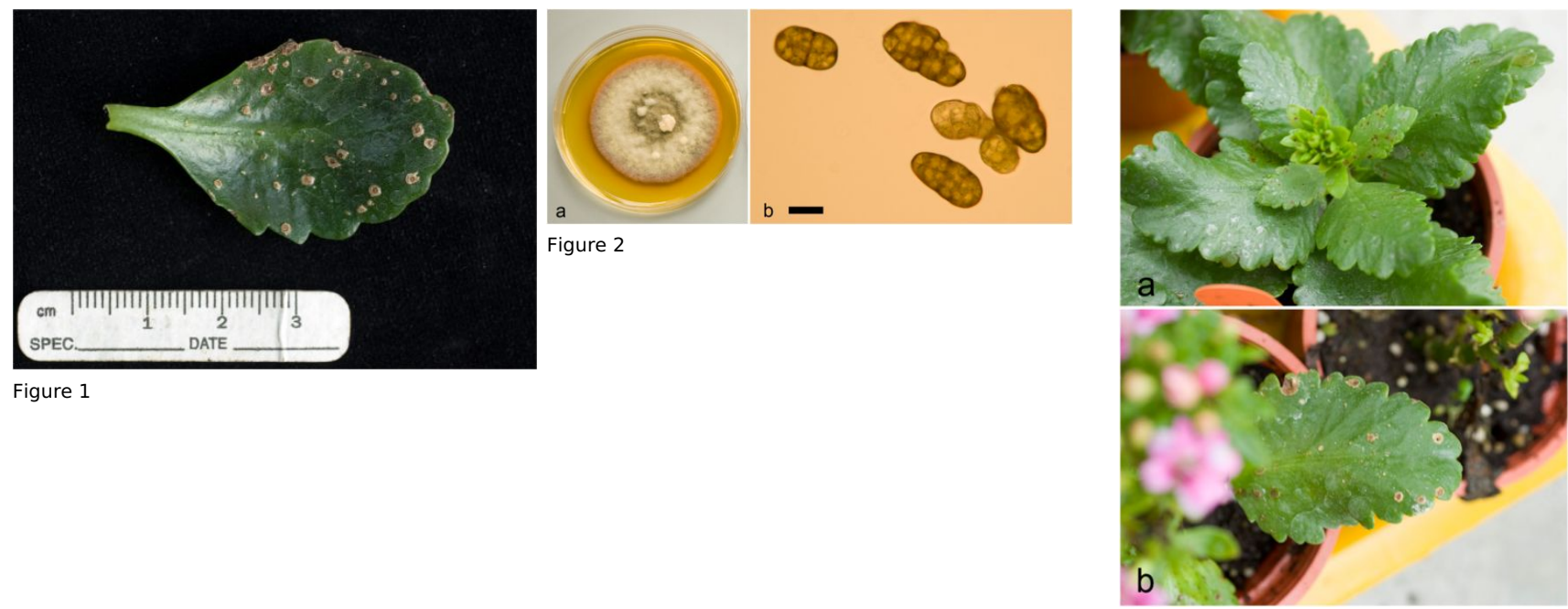

Figure 3

To cite this report: Shen YM, Yang YC, Fu YJ, Hung TH, 2012. First report of Stemphylium solani causing leaf spot of Kalanchoe blossfeldiana in Taiwan. New Disease Reports 25, 10. [doi:10.5197/j.2044-0588.2012.025.010]

(c)2012 The Authors

This report was published on-line at www.ndrs.org.uk where high quality versions of the figures can be found. 